\title{
Ex Vivo accuracy of an endodontic motor with an integrated apex locator in multirooted teeth: Research article
}

\author{
Alex Lvovsky ${ }^{1}$, Gabriel Batashvili ${ }^{1}$, Simone Staffoli ${ }^{2}$, Barbara G Nunez Torrijos²*, Gianluca Gambarini ${ }^{2}$, Michael Solomonov ${ }^{1}$ and Joe Ben \\ Itzhak $^{1}$ \\ ${ }^{1}$ Department of Endodontics, Israel Defense Forces Medical Corps, Sheba Hospital, Tel Hashomer, Ramat Gan, Israel \\ ${ }^{2}$ Department of Oral and Maxillo-Facial Science, “Sapienza”- University of Rome, Rome, Italy
}

\begin{abstract}
Background: Endodontic motors with an integrated electronic apex locator have been tested for its accuracy mostly on single-rooted teeth. Multirooted teeth may create interferences on the readings created by the irrigation solution in the pulp chamber and additional canals. This study aimed to examine in vitro the accuracy of an integrated endodontic motor with an EAL attached in multirooted teeth.

Methods: Extracted teeth on a model specially developed to test EALs were tested. The actual working length (WL) was measured with a $5 \mathrm{x}$ microscope and K-Files, EAL working length was measured with the pulp chamber flooded with sodium hypochlorite and the measure obtained shaping root canals with the auto apical reverse (AAR) mode, (an endodontic motor that attached to an EAL starts auto-reverse mode when the working length defined by the EAL is reached), was registered taking $\mathrm{x}$-rays to the obturated teeth after the root canal cleaning and shaping.
\end{abstract}

Results: No statistically significant difference was found between the three groups. When a $0.5 \mathrm{~mm}$ difference between the true and measured WL was set as a correct reading, 13 out of 26 canals were measured correctly in both the EAL and obturation measurements. When the reading was set at a difference of $1 \mathrm{~mm}$ or less, the EAL correctly measured 20 out of 26 canals, while the obturation WL was correct in 16 out of 26 canals.

Conclusion: Further studies with a larger sample size are needed to elucidate the accuracy of integrated motor-EAL units more profoundly.

\section{Introduction}

Root canal treatment (RCT) procedures should be confined within the root canal system [1]. The working length (WL) is defined as the distance between a coronal reference point and the point at which canal preparation and obturation should terminate [2]. Maintaining a correct WL during RCT is expected to influence the outcome of RCT positively $[3,4]$. Thus, the WL should be measured as precisely as possible. Electronic root canal length measuring devices (electronic apex locators [EALs]) offer a means of locating the WL for root canal procedures. The reliability of double-frequency EALs in determining the position of the apical foramen (AF) is superior to the radiographic method [5].

In the past decades, devices that integrate an electronic apex locator with an endodontic electrical motor for canal preparation have been introduced. By stopping the rotation of the nickel-titanium (NiTi) files when the point estimated to be the end of the root canal is reached, these apex-locator-controlled endodontic motors eliminate the need to verify working length with multiple files and avoid the imprecision of using a reference point on the tooth. These devices can be used either as regular apex locators (with manual hand files) or for operating rotary NiTi files using the motor-controlled mode [6]. Some devices also allow the operator to select the apical position of choice and have a reverse motion to help to remove the file from the canal when the apex is reached or in case of canal blockage [7].
Unfortunately, most studies examining the accuracy of such integrated devices were conducted on single-rooted teeth [7-9]. Multi rooted teeth may present a greater challenge due to the possible interference to the EAL reading created by irrigation solution in the pulp chamber and additional canals $[10,11]$.

This study aimed to examine in vitro the accuracy of an integrated endodontic motor with an EAL attached in multi-rooted teeth.

\section{Materials and methods}

Ten recently extracted human teeth were randomly selected for this study. The teeth were kept in a $0.9 \% \mathrm{NaCl}$ solution until preparation. Access cavities were prepared (Tungsten carbide 1157, SS White Burs, NJ, USA). The actual working length (WL) was measured with the aid of a binocular microscope X 5 (Wild M_8, Leitz LTD, Heerbrugg, Switzerland) by introducing a no. 10 or no. $15 \mathrm{~K}$-file until it emerged from the apical foramen and then retracted $1 \mathrm{~mm}$ coronally. Each

*Correspondence to: Barbara G Nunez Torrijos, Department of Oral and Maxillo-Facial Science, "Sapienza"- University of Rome, Rome, Italy, Tel: +39 3339984529; E-mail: bnuneztorrijos@gmail.com

Key words: endodontics, root canal, tooth apex

Received: January 20, 2020; Accepted: February 20, 2020; Published: February 24,2020 
measurement was repeated three times, and the mean value computed. Teeth were embedded in an alginate model specially developed to test apex locators (Kaufman \& Katz 1993). The model consisted of a plastic box (a photograph slide box, $10 \times 3 \times 3 \mathrm{~cm}$ ) with a perforation on the lid. Alginate (Blue Print normal set, Dentsply, Weybridge, UK) was poured into the box, and the frame-lid with the teeth put inside of the perforation at CEJ level was embedded into the alginate. The teeth were stabilized using composite resin in order to prevent movement during preparation.

For each canal, an EAL working length was measured by introducing a \#15 K-file connected to an EAL (Dual Pex, Micro Méga, Besançon, France) into the canals while the pulp chamber was flooded with a $3 \% \mathrm{NaOCl}$ solution. The file was advanced into the canal until "apex" was displayed and then retracted $1 \mathrm{~mm}$ coronally. Afterward, the canals were rinsed with $3 \% \mathrm{NaOCl}$.

An operator blinded to the true WL measurements used an endodontic motor (Dual Move, Micro Méga, Besançon, France) connected to the same EAL and One Curve (Micro Méga, Besançon, France) endodontic rotary single file system to prepare the canals. The motor was set to operate in accordance with the file manufacturer's instructions, i.e., $350 \mathrm{rpm}$ with a $2.5 \mathrm{~N} / \mathrm{Cm}$ torque setting. The motor was also set to auto-reverse when WL was reached. The canals were prepared up to the WL as determined by this setup, with $\mathrm{NaOCl}$ flooding the pulp chamber and a $\mathrm{NaOCl}$ rinse after each introduction of the file into the canals.

The canals were dried by paper points and obturated to the prepared WL using MM SEAL (Micro Méga, Besançon, France) and a single tapered Gutta Percha point (Hygenic MF, Hygenic, Akron, OH, USA)

A radiograph was taken in order to determine the apical position of the obturation material.

The obturation working length was established by radiographically measuring the apical extent of the obturation material.

\section{Results}

Ten teeth with a total of 26 canals were eligible for examination. The mean true WL was $18.4 \mathrm{~mm}$, while the mean EAL WL was $18.2 \mathrm{~mm}$ and the mean obturation WL was $19.0 \mathrm{~mm}$.

The mean difference between the true and measured WL was 0.17 $\mathrm{mm}$ for the EAL measurement and $0.66 \mathrm{~mm}$ for the measurement of obturation (Table 1).

The Shapiro-Wilk test determined the distribution of data. The data was not normally distributed; thus, an independent sample MannWhitney $U$ test was used to determine the statistical significance. No statistically significant difference was found between the true, EAL, and obturation WL.

When a $0.5 \mathrm{~mm}$ difference between the true and measured WL was set as a correct reading, 13 out of 26 canals were measured correctly in both the EAL and obturation measurements (Table 2).

When a "correct" reading was set at a difference of $1 \mathrm{~mm}$ or less between the measured and true WL, the EAL correctly measured 20 out of 26 canals, (Figure 1 and Table 3) while the obturation WL was correct in 16 out of 26 canals. A chi-square test was performed with no significant difference detected between the groups.
Table 1. Mean difference between the true and measured WL

\begin{tabular}{|c|c|}
\hline \multicolumn{2}{|c|}{ Mean difference from true WL $(\mathrm{mm})$} \\
\hline EAL & 0.17 \\
\hline XRAY & 0.66 \\
\hline
\end{tabular}

Table 2. Correct reading between the true and measured WL

\begin{tabular}{|c|c|c|}
\hline \multicolumn{3}{|c|}{ Was the measurement within $0.5 \mathrm{~mm}$ of true WL? } \\
\hline & NO & YES \\
\hline EAL & 13 & 13 \\
\hline XRAY & 13 & 13 \\
\hline
\end{tabular}

Table 3. Difference of measured and true WL

\begin{tabular}{|c|c|c|}
\hline \multicolumn{3}{|c|}{ Was the measurement within $1 \mathrm{~mm}$ of true WL? } \\
\hline & NO & YES \\
\hline EAL & 6 & 20 \\
\hline XRAY & 10 & 16 \\
\hline
\end{tabular}

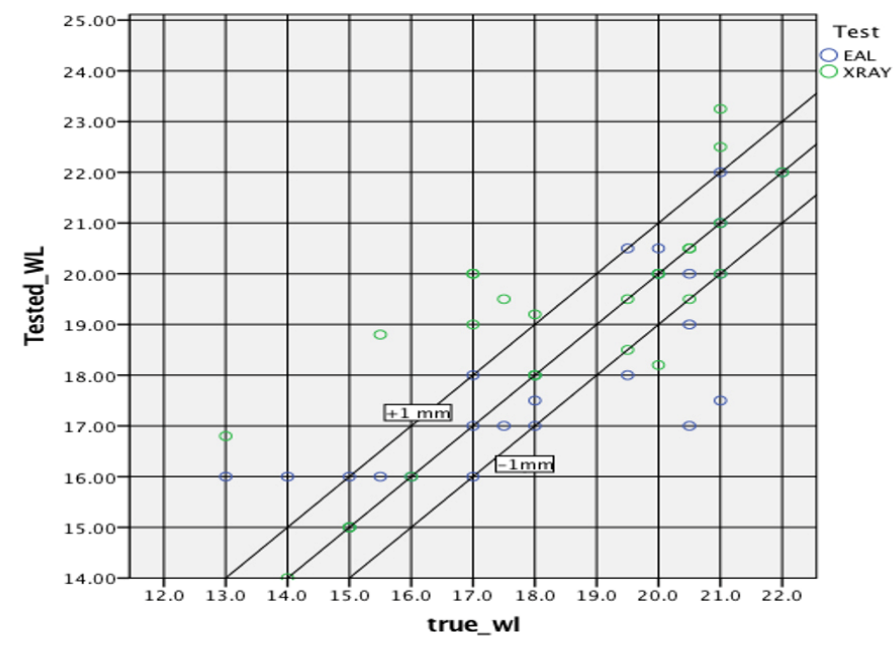

Figure 1. A chi-square test

\section{Discussion}

According to the recommendation of the European Society of Endodontology (2006), the apical constriction is recommended as the end-point of root canal treatment [12].

Apical termination of root canal is a very controversial landmark since there is not real evidence-based knowledge to confirm a real standard ending for the canal debridement. There are philosophies that follow anatomical studies, treatment outcomes, empirical directives, or status of the dental pulp and peri apical tissues. Since it has been encountered a delay on the healing time in obturations over the apical constriction, it would be a good practice to establish the working length as close to the constriction as possible [13]. This position has been claimed to be as approximately $0.5-1.0 \mathrm{~mm}$ from the radiographic apex [1].

Apex locators have advantages over radiographic methods; Electronic working length (EWL) determination with apex locators is more comfortable, faster and can be indefinitely repeated without exposure to radiation. The accuracy of apex locators is higher when compared with that of the radiographic methods [14].

Nevertheless, it has been shown that a higher accuracy can be reached when both radiographic and EWL determination is performed. A working length radiograph after EWL determination can reduce over instrumentation and provide valuable diagnostic information. 
Radiographic verification of the EWL is essential because, in some clinical situations, apex locators give incorrect readings [14,15].

The objective of this study was to evaluate the accuracy of the Dual Pex EAL and the Dual Pex EAL combined with the Dual Move motor in multi-rooted teeth.

For the present study, multi-rooted molar teeth were selected, as they were considered more challenging for clinical practice than singlerooted teeth, which were used in most of the previous studies [16-18].

Some studies observed that using EALs coupled to rotating files during shaping was not as reliable as using only the EAL function with hand files [6-19]. It has been suggested that the accuracy of the auto apical reverse (AAR) could be hampered by the increased impedance of the root canals (because of the occlusion of dentin tubules by the smear layer or guttapercha) or because the electronic measurement requires some time to process the position of the instrument inside the root canal $[6,8,20]$.

In the present study, the mean difference between the true and measured WL was $0.17 \mathrm{~mm}$ for the EAL measurement without the motor, a clinically acceptable result. In contrast, the obturation WL after preparation with the EAL connected to the motor differed by a mean of $0.66 \mathrm{~mm}$ from the true WL, more than the $0.5 \mathrm{~mm}$ limit deemed acceptable by some studies [21].

In multi-canal teeth, the irrigation solution may "short circuit" the EAL reading due to the electrically conducting nature of the irrigant and thus influence the reading of the EAL. This may explain why some studies found that an accurate reading was easily obtained in dry canals as opposed to canals flooded with irrigant $[22,23]$.

When a $0.5 \mathrm{~mm}$ difference between the true and measured WL was set as a correct reading, 13 out of 26 canals (50\%) were measured correctly by both the EAL and the EAL connected to the endodontic motor. Furthermore, when a more lenient cutoff of $1 \mathrm{~mm}$ accuracy was considered, the EAL alone correctly detected the WL in 20 out of 26 canals (77\%), whilst when the same EAL was was attached to an endodontic motor, the accuracy was reduced to 16 out of 26 canals $(61 \%)$ as determined by the eventual obturation ( $p>0.05)$ [24].

The difference between methods of WL measurement if not statistically significant in our results but increasing the sample size may result in different results.

One possible explanation can be the interference created by the irrigation solution in the canals. Furthermore, there may be a timelapse between the detection of the AF by the integrated EAL and the subsequent change in rotation direction by the motor, resulting in a "longer" preparation and finally this methodic lack of the tactile sensation of the manual preparation that offers more precise control [25].

In conclusion, further studies with a larger sample size are needed to elucidate the accuracy of integrated motor-EAL units in a deeper way.

\section{References}

1. Ricucci D (1998) Apical limit of root canal instrumentation and obturation, part 1. Literature review. Int Endod J 31: 384-393. [Crossref]

2. Ricucci D, Langeland K (1998) Apical limit of root canal instrumentation and obturation, part 2. A histological study. Int Endod J 31: 394-409. [Crossref]

3. Sjogren U, Hagglund B, Sundqvist G, Wing K (1990) Factors affecting the long-term results of endodontic treatment. J Endod 16: 498-504. [Crossref]

4. Georgopoulou M, Anastassiadis P, Sykaras S (1986) Pain after chemomechanical preparation. Int Endod J 19: 309-314.
5. Nekoofar MH, Ghandi MM, Hayes SJ, Dummer PM (2006) The fundamental operating principles of electronic root canal length measurement devices. Int Endod J 39: 595609. [Crossref]

6. Siu C, Marshall JG, Baumgartner JC (2009) An in vivo comparison of the Root ZX II, the Apex NRG XFR, and Mini Apex Locator by using rotary nickel-titanium files. $J$ Endod 35: 962-965. [Crossref]

7. Barthelemy J, Gregor L, Krejci I, Wataha J, Bouillaguet S (2009) Accuracy of electronic apex locater-controlled handpieces. Oral Surg Oral Med Oral Pathol Oral Radiol Endod 107: 437-441. [Crossref]

8. Uzun O, Topuz O, Tinaz C, Nekoofar MH, Dummer PM (2008) Accuracy of two roo canal length measurement devices integrated into rotary endodontic motors when removing gutta-percha from root-filled teeth. Int Endod J 41: 725-732. [Crossref]

9. Gehlot PM, Manjunath V, Manjunath MK (2016) An in vitro evaluation of the accuracy of four electronic apex locators using stainless-steel and nickel-titanium hand files. Restor Dent Endod 41: 6-11. [Crossref]

10. Saraf PA, Ratnakar P, Patil TN, Penukonda R, Kamatagi L, et al. (2017) A comparative clinical evaluation of accuracy of six apex locators with intraoral periapical radiograph in multirooted teeth: An in vivostudy. J Conserv Dent 20: 264-268. [Crossref]

11. Milanovic I, Ivanovic V, Vujaskovic M, Ignjatovic S, Miletic V (2015) Accuracy of three electronic apex locators in determining the apical foramen in multi-rooted teeth: Randomised clinical and laboratory study. Aust Endod J 41: 35-43. [Crossref]

12. European Society of Endodontology (2006) Quality guidelines for endodontic treatment: consensus report of the European Society of Endodontology. Int Endod J 39: 921-930. [Crossref]

13. Gutmann JL (2016) Apical termination of root canal procedures-ambiguity or disambiguation? Evidence-Based Endodontics 1: 4.

14. Vasconcelos BC, Bastos LM, Oliveira AS, Bernardes RA, Duarte MA, et al. (2016) Changes in root canal length determined during mechanical preparation stages and their relationship with the accuracy of root ZX II. J Endod 42: 1683-1686. [Crossref]

15. ElAyouti A, Dima E, Ohmer J, Sperl K, von Ohle C, et al. (2009) Consistency of apex locator function: a clinical study. J Endod 35: 179-181. [Crossref]

16. Ozsezer E, Inan U, Aydin U (2007) In vivo evaluation of ProPex electronic apex locator. J Endod 33: 974-977. [Crossref]

17. Stoll R, Urban-Klein B, Roggendorf MJ, Jablonski-Momeni A, Strauch K, et al. (2010) Effectiveness of four electronic apex locators to determine distance from the apical foramen. Int Endod J 43: 808-817. [Crossref]

18. Altenburger MJ, Tchorz JP, Somma F (2012) In vivo accuracy of three electronic roo canal length measurement devices: Dentaport ZX, Raypex 5 and ProPex II. Int Endod J 45: 1053-1054. [Crossref]

19. Felippe WT, Felippe MC, Reyes JC, Crozoé FC, Alvisi BB (2008) Ex vivo evaluation of the ability of the ROOT ZX II to locate the apical foramen and to control the apical extent of rotary canal instrumentation. Int Endod J 41: 502-507. [Crossref]

20. Al-bulushi A, Levinkind M, Flanagan M, Ng YL, Gulabivala K (2008) Effect of canal preparation and residual root filling material on root impedance. Int Endod J 41: 892904. [Crossref]

21. Fouad AF, Krell KV, McKendry DJ, Koorbusch GF, Olson RA (1990) Clinical evaluation of five electronic root canal length measuring instruments. J Endod 16: 446449. [Crossref]

22. Kang JA, Kim SK (2008) Accuracies of seven different apex locators under various conditions. Oral Surg Oral Med Oral Pathol Oral Radiol Endod 106: 57-62. [Crossref]

23. Haffner C, Folwaczny M, Galler K, Hickel R (2005) Accuracy of electronic apex locators in comparison to actual length--an in vivo study. J Dent 33: 619-625. [Crossref]

24. Keller ME, Brown CE Jr, Newton CW (1991) A clinical evaluation of the Endocater-an electronic apex locator. $J$ Endod 17: 271-274. [Crossref]

25. Uzun O, Topuz O, Tinaz AC, Alaçam T (2007) Apical accuracy of two apex-locating handpieces in root canal retreatments of root-end resected teeth. $J$ Endod 33: 1444 1446. [Crossref]

Copyright: (C2020 Lvovsky A. This is an open-access article distributed under the terms of the Creative Commons Attribution License, which permits unrestricted use, distribution, and reproduction in any medium, provided the original author and source are credited. 